\title{
The Aging Midface and the Role of Lower Lid Blepharoplasty
}

\author{
Vito Quatela C, MD, FACS* and Nigar Ahmedli N, MD \\ Quatela Center for Plastic Surgery, 973 East Avenue, Rochester, NY 14607, USA
}

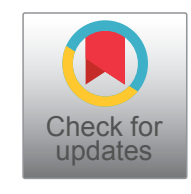

\begin{abstract}
Aging of the midface has been described to involve soft tissue descent as well as volumetric change. A simplified grading system for midfacial ptosis ranging from mild to severe has recently been proposed. Midfacial ptosis results in exposure of the orbital rim and the creation of a more acute orbital rim angle, especially in conjunction with orbital fat pseudoherniation. In the authors' opinion, the best surgical approach to address severe midfacial ptosis is the transtemporal subperiosteal midface lift in combination with a fat-modifying transconjunctival lower lid blepharoplasty with skin pinch. In regard to the ability to efface the orbital rim, the authors compare the transtemporal subperiosteal midface lift with transconjunctival lower lid blepharoplasty with skin pinch with the lower lid blepharoplasty with fat transposition. Both techniques establish equal outcomes in correcting the orbital rim angle.
\end{abstract}

\section{Theories of Aging Midface}

Aging of the midface has been described to involve soft tissue descent as well as volumetric change [1]. In the gravitational theory of the midfacial aging, vertical descent of soft tissue due to ligamentous attenuation is thought to contribute to the deep folds [2]. Ligaments within the cheek that affix the dermis to the underlying fibro-osseous structures were described by Furnas in 1989 [3]. The attenuation of these ligaments, age-related elastosis and the repeated animation of facial mimetic muscles were thought to contribute to midfacial soft tissue descent [4]. Furthermore, using magnetic resonance imaging, Gosain et al. showed a relative descent in cheek fat pad position in older faces ( $>60$ years) compared to younger ones (16-30 years) [5].

In contrast to the gravitational theory, Lambros described a volumetric theory of midfacial aging in 2007. In his analysis of 130 patients photographed 10-56 years apart, Lambros noted that the lid-cheek junction remained stable and the periorbital and upper midface skin landmarks did not descend. He therefore proposed that the fibrous network of the face is relatively immobile. Lambros suggested that the changing morphology of the midface was the result of the relative deflation or atrophy of specific fat pads rather than gravitational soft tissue descent [6]. This echoed Donofrio's proposition that the periorbital, buccal, and perioral fat atrophy with aging [7]. Furthermore, Rohrich et al noted that older patients display excess fat in superficial compartments including the infraorbital, lateral temporal cheek, and submental fat with a concomitant deflation of deep cheek fat [8].

In addition to the soft tissue changes described above, bony changes have also been shown to occur in midfacial aging. This includes the retrusion of the maxilla, as described using computed tomography studies $[9,10]$. The orbital rim aperture widens secondary to varying resorption of the superomedial, inferolateral and inferomedial aspects of the orbital rim $[9,11]$.

It is important to recognize that midfacial aging is likely a combination of gravitational and volumetric changes of the soft tissue as well as the underlying bony changes. While Lambros noted the stability of lid-cheek junction and certain facial landmarks based on photographic evidence, the enlargement of the orbital aperture that occurs with aging was not addressed. While the involution and ptosis of the soft tissue paired with a larger orbital aperture give the appearance of a stable lid-cheek junction, a component of gravitational descent is present.

\section{Definition of Midfacial Ptosis}

The midface, or the vertical middle third of the face, is comprised of the lower eyelid, the bony orbital rim, the maxilla, malar and suborbicularis oculi fat (SOOF) pads, and mimetic muscles, including the orbicularis oculi, zygomaticus

* Corresponding author: Dr. Vito Quatela C, MD, FACS, Quatela Center for Plastic Surgery, 973 East Avenue, NY 14607, Rochester, USA, Tel: (585)-244-2952, Fax: (585)-271-4786

Accepted: August 16, 2021

Published online: August 18, 2021

Citation: Vito QC, Nigar AN (2021) The Aging Midface and the Role of Lower Lid Blepharoplasty. J Ophthalmic Surg 4(1):35-42 

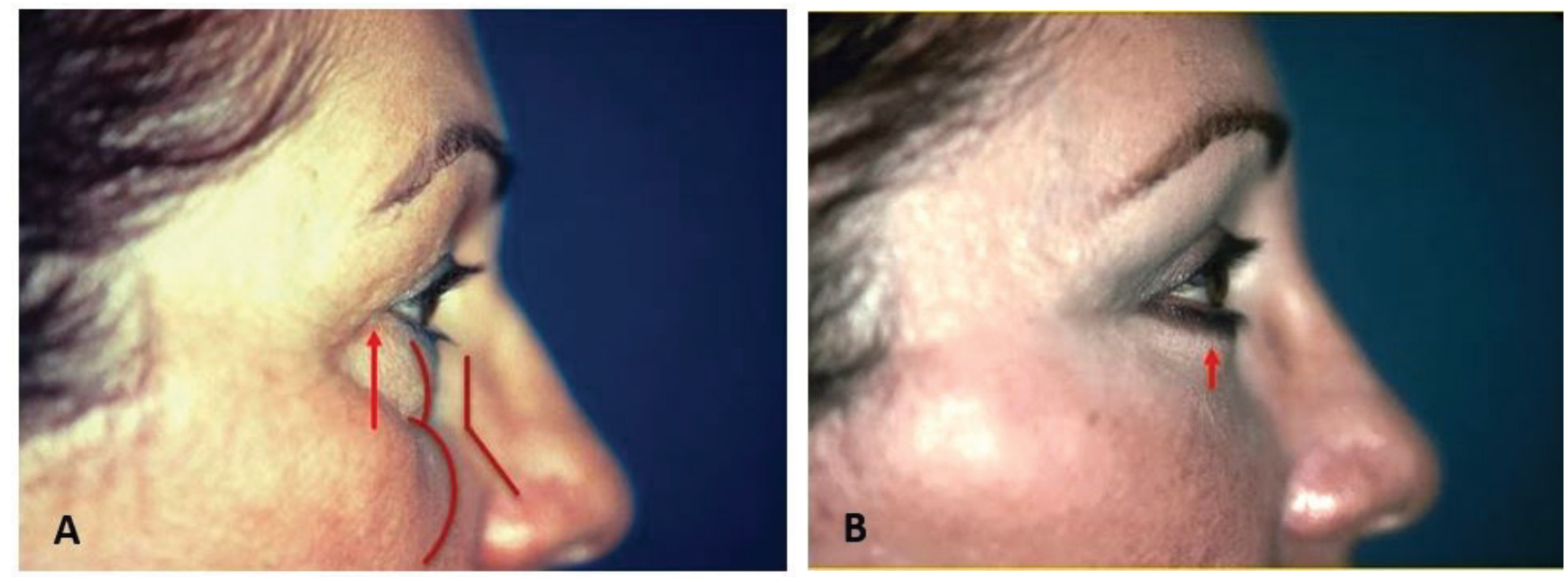

Figure 1: Orbital Rim Angle.

The orbital rim angle is measured as the angle between the line tangent to the double convexity of the orbital fat pseudoherniation and the line tangent to the descended SOOF at the inferior orbital rim; A) The arrow shows the decrease in the length of the thin lower lid skin before; A) and after; B) a transtemporal subperiosteal midface lift with transconjunctival lower lid blepharoplasty with skin pinch.

major and minor, and masseter. The soft tissue structures of the malar fat pad and SOOF constitute the fatty component of the midface. The lower lid-cheek junction is represented by a curved line that runs inferior and parallel to the infraorbital rim, delineating the transition between the palpebral and orbital divisions of the orbicularis oculi muscle [12]. The skin of the lower eyelid superior to this junction is thin and directly lies over the muscle while the skin inferior to this junction is thicker and separated from the muscle by the malar fat pad [12]. The orbicularis oculi muscle attaches firmly to the bony orbital rim along the medial aspect of the lid-cheek junction. Laterally between the medial limbus and mid-pupillary line in the area of the SOOF, the muscle attaches to the orbicularis retaining ligament, which in turn attaches to the bony orbital rim [12]. The SOOF is comprised of two compartments: the medial compartment extending from the medial limbus to the lateral canthus, and the lateral compartment extending from the lateral canthus to the temporal fat pad [3]. The malar fat pad contains a triangular thickening of the subcutaneous fat in the cheek superficial to the superficial musculoaponeurotic system (SMAS) overlying the maxilla, which constitutes the majority of the midface volume [12]. The zygomaticus major and minor muscles are enveloped by the SMAS and are located superficial to the SOOF and deep to the malar fat pads. The sum of these parts creates the contour of youthful midface, which appears as a single continuous smooth convexity extending from the lower lid margin to the oral commissure [13].

A description of midfacial aging must include a discussion of the changes that occur within the orbital fat. It is commonly accepted that the orbital septum weakens with aging, allowing for orbital fat protrusion [14]. The lower eyelids develop palpebral bags resulting from the pseudoherniation of orbital fat against a weak orbital septum [15]. The laxity of the orbicularis oculi muscle and its attachments increase, allowing for further accentuation of the pseudoherniation. The arcus marginalis, however, remains tightly adherent to the bony orbital rim in contrast to the protrusion of the orbital septum and the descent of the malar mounds [14]. Therefore, with orbital rim exposure, the prolapsed orbital fat in the lower lid complex and ptotic SOOF create a double convexity contour [16]. This double convexity contour can be quantified by measuring the angle at the orbital rim between the two convexities in profile view, which has been termed the orbital rim angle (Figure 1). In other words, the angle at which the tangents to each convexity intersect at the inferior orbital rim is measured. A smooth convex contour in profile view is seen when the orbital rim angle is greater than 180 degrees [13]. Therefore, the attachment of the arcus marginalis at the orbital rim contributes greatly to the aged appearance of the midface [14]. Inferior to the orbital rim, malar mounds may form and descend, accentuating the nasolabial folds [15].

In contrast to the pseudoherniation and orbital rim exposure described above as a major contributor to midfacial aging, Darcy et al showed using magnetic resonance imaging that the anterior and inferior regions of orbital fat volume increase with age [17]. Using cadaveric specimens, Rohrich demonstrated that the injected methylene blue was restricted to a small anterior compartment deep to the lower eyelid without extension into the fat within the orbital cone and appeared to be separated from the deeper orbital fat by a distinct fascial layer [18]. These studies challenge the traditional description that pseudoherniation of orbital fat compartments and the widening orbital rim are the predominant contributors to lower lid and midfacial aging. ${ }^{13}$ Thus, aging is likely a combination various factors which differ among individuals.

\section{Midfacial Ptosis Grading System}

Recently, we proposed a new grading system of midfacial ptosis given the lack of an established and widely used classification [19]. In summary, grade I is characterized as mild ptosis (Figure 2). The midface is comprised of shallow nasolabial folds, minimal recession at the pyriform aperture, 

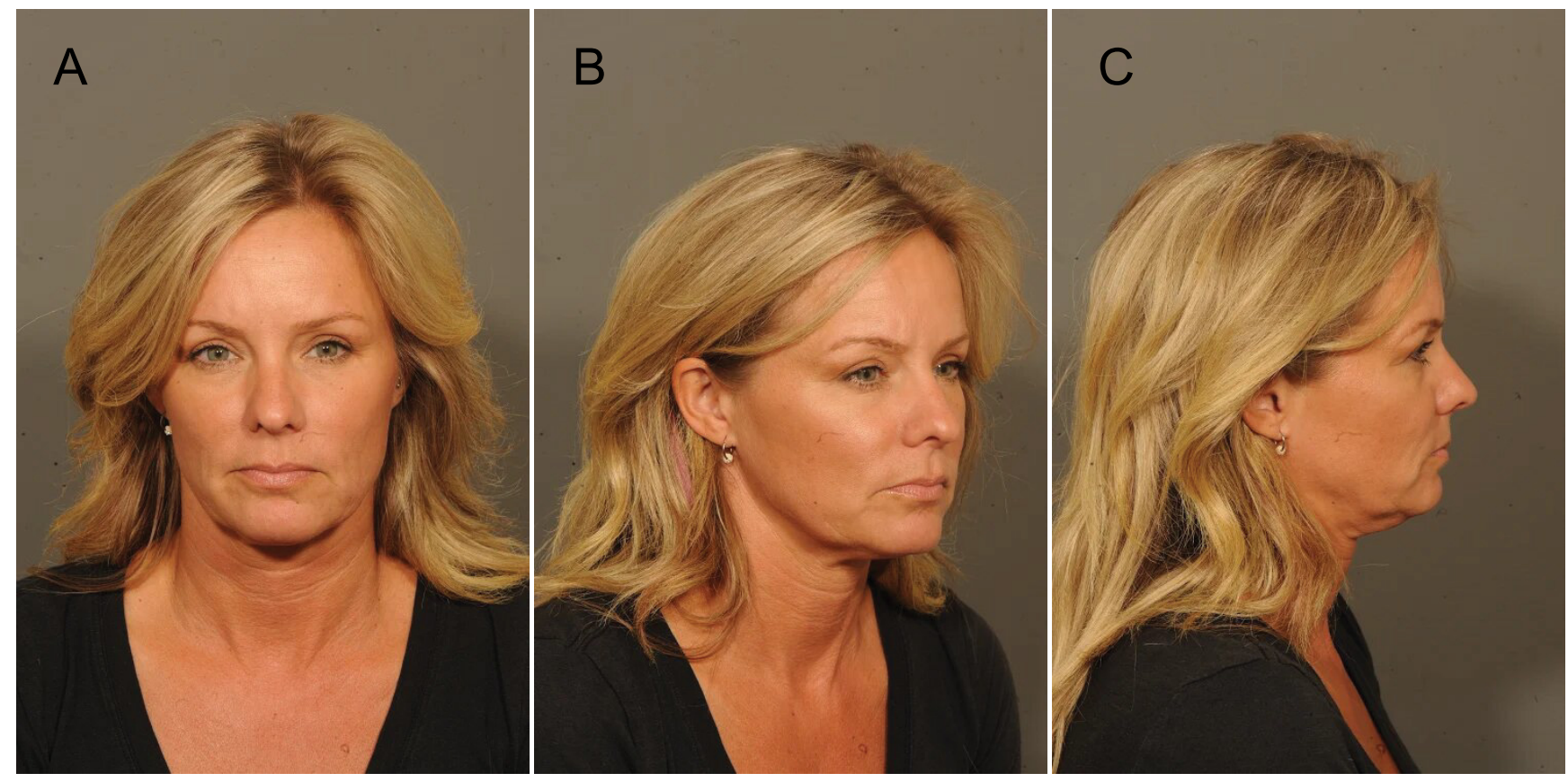

Figure 2: Grade I midfacial ptosis Grade.

I ptosis is characterized by shallow nasolabial folds, minimal recession at the pyriform aperture, mild ptosis of the malar fat pads, and mild orbital rim exposure.
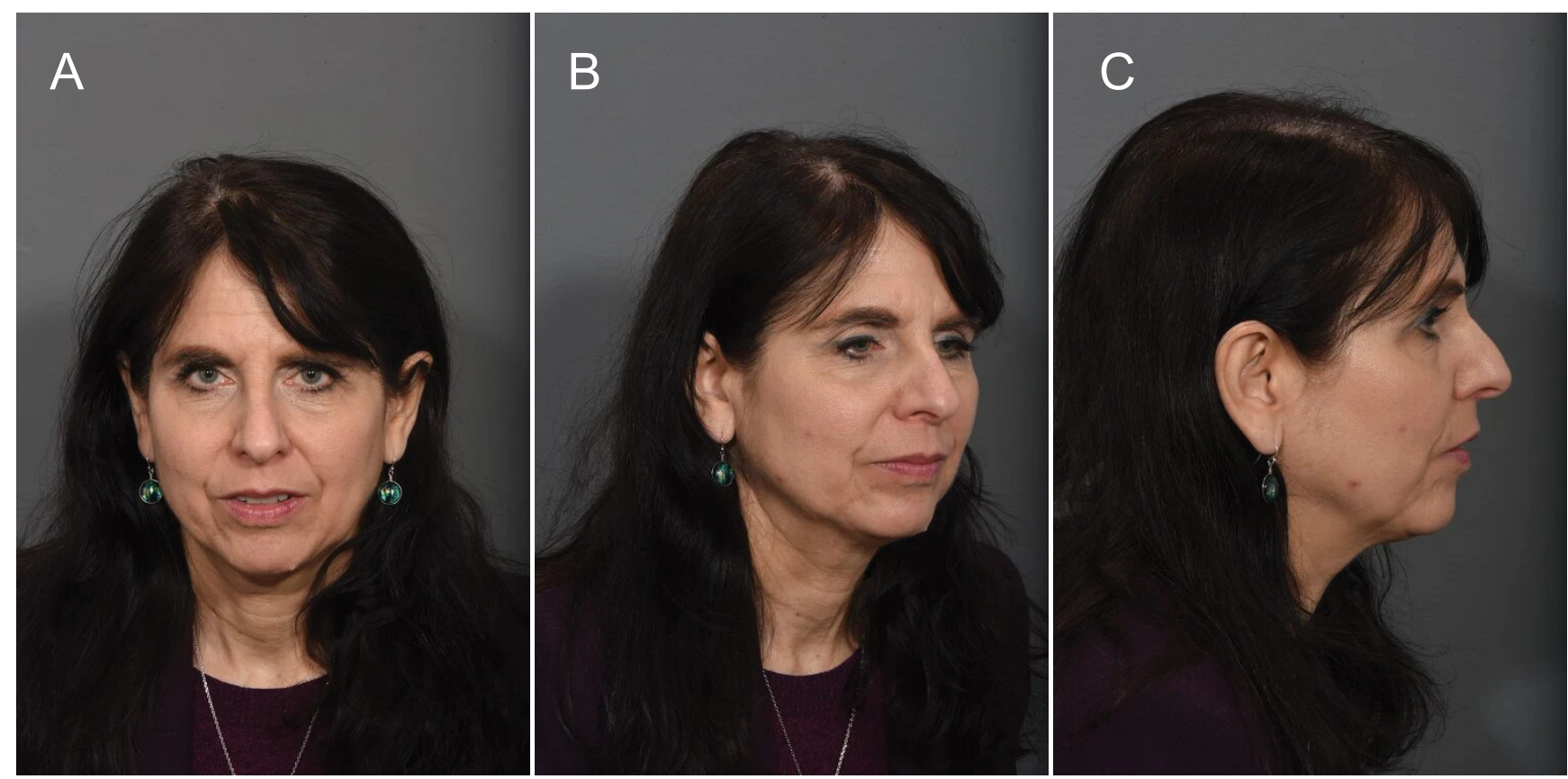

Figure 3: Grade II midfacial ptosis.

Grade II ptosis is characterized by deep nasolabial folds, a pronounced recession at the pyriform aperture, moderate ptosis of the malar fat pads including noticeable partitions of the fat pad septations, and the beginnings of a double convexity contour of the orbital rim.

mild ptosis of the malar fat pads without partitions of the fat pad septations, and mild orbital rim exposure with the midfacial contour still appearing as a single convexity [19].

Grade II describes moderate ptosis (Figure 3). The aging midface includes deep nasolabial folds, a pronounced recession at the pyriform aperture, moderate ptosis of the malar fat pads including visible partitions of the fat pad septations, and an apparent double convexity contour of the orbital rim. The midfacial contour includes several undulations, incorporating concavities into the contour [19]. 

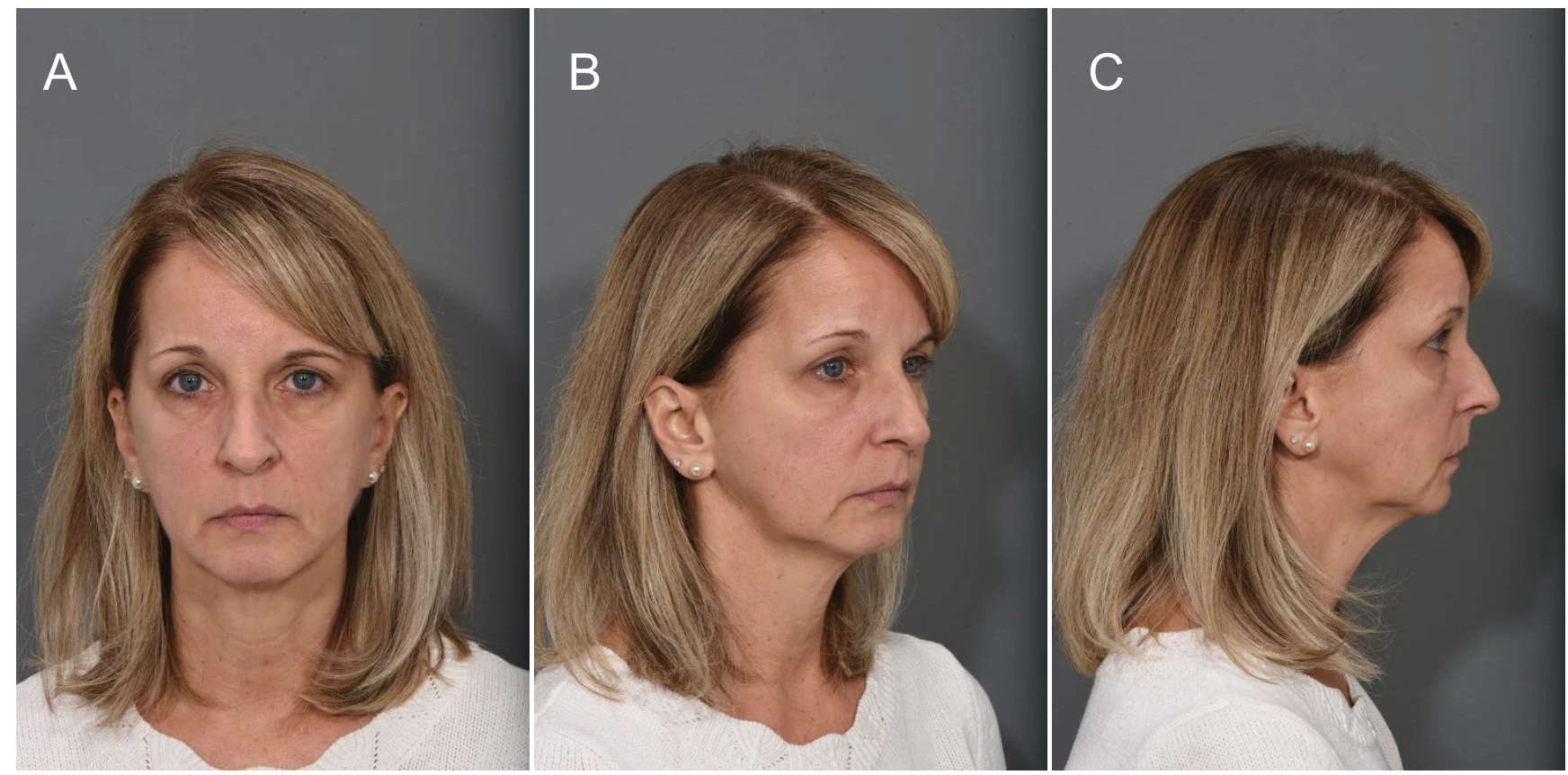

Figure 4: Grade III midfacial ptosis.

Grade III ptosis is characterized by deep nasolabial folds, significant retrusion at the pyriform aperture, significant ptosis of the malar fat pads with pronounced atrophy and partitions, and a dramatic double convexity contour of the orbital rim.

Grade III describes severe ptosis (Figure 4). The profoundly aged midface consists of deep nasolabial folds, pronounced retrusion at the pyriform aperture, substantial ptosis of the malar fat pads with apparent atrophy and distinct partitions, and a remarkable double convexity contour of the orbital rim. The midfacial contour is composed of demarcated divisions between its convex and concave aspects and is separate from the malar prominence [19].

\section{A Discussion of Surgical Approaches}

Cases of grade III midfacial ptosis present a challenge best addressed by the authors with a transtemporal subperiosteal midface lift. The advantages of this technique include improved lifting of the malar fat pads and the SOOF given the subperiosteal plane of dissection. This technique effaces the pseudoherniation of the orbital fat pads, effectively contouring the inferior orbital rim. The subperiosteal dissection allows the periosteum to be secured in a more superior position, significantly increasing the longevity of the lift [12]. The more vertical orientation of the elevation vector is more effective in raising the midfacial fat pads [20]. Despite the longer recovery time and transient lateral canthal distortion of the midface lift, its benefits for severe midfacial ptosis are exceptional. The transtemporal midface lift also has an added benefit of decreasing the vertical height of the lower lid [21] as well as an elevation of the lower lid-cheek junction with the addition of a transconjunctival lower lid blepharoplasty with skin pinch [22]. This emphasizes that the role of lower eyelid treatment is integral to the perception of midfacial ptosis.

Both a transtemporal subperiosteal midface lift with transconjunctival lower lid blepharoplasty with skin pinch and lower lid blepharoplasty with fat transposition can improve the orbital rim angle to achieve a more youthful, smooth convexity. The midface lift approach attempts to restore the anatomical position of the midfacial soft tissues while a lower lid blepharoplasty with fat transposition camouflages the orbital rim angle by re-positioning the orbital fat over the inferior orbital rim.

In a recent study, the average pre-operative orbital rim angle in patients undergoing a transtemporal midface lift with lower lid skin pinch was $132.2^{\circ}$ and $131.5^{\circ}$ in those undergoing a lower lid blepharoplasty with fat transposition [13]. Post-operatively, the average orbital rim angle in the transtemporal midface lift group was $181.2^{\circ}$ and $175.7^{\circ}$ in the lower lid blepharoplasty with fat transposition group, which was not statistically significant $(p=0.90)$ [13]. Thus, both techniques allow for restoration of the youthful orbital rim angle (Figure 5). The selection of the technique most appropriate for the patient depends on various factors. For example, in patients with brow ptosis and prominent corrugator activity, the transtemporal midface lift is better suited as it can address these issues as well as the orbital rim angle [13]. Patients who prefer a less invasive procedure with a shorter recovery time and are only bothered by the palpebral bags are better candidates for the lower lid blepharoplasty with fat transposition.

\section{Surgical Techniques}

The following procedures can be performed under local anesthesia with deep sedation or general anesthesia. Prior to incision, the subcutaneous plane of lower eyelids is infiltrated with a local solution consisting of $50 \mathrm{cc}$ of $1 \%$ Lidocaine, $50 \mathrm{cc}$ of $0.25 \%$ Marcaine, $50 \mathrm{cc}$ normal saline, $10 \mathrm{cc}$ of Tranexamic Acid $100 \mathrm{mg} / \mathrm{mL}$ and $1 \mathrm{cc}$ of Epinephrine 1:1000. For the 

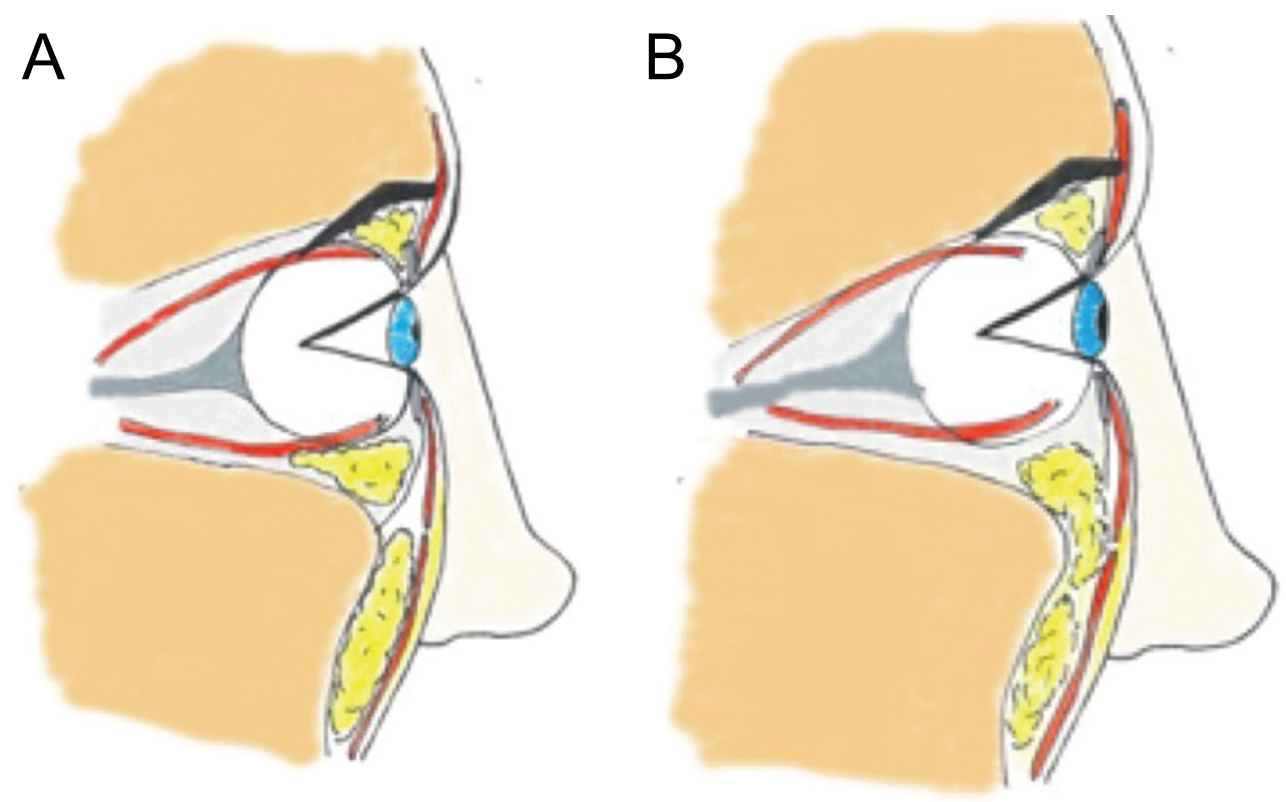

\section{Transtemporal midface lift}

\section{Lower blepharoplasty with fat transposition}

Figure 5: Comparison of the transtemporal subperiosteal midface lift and lower lid blepharoplasty with fat transposition.

In the midface lift, the vertical position of the ptotic malar fat pads is restored (A) whereas in the lower lid blepharoplasty with fat transposition, the orbital fat pads are re-positioned over the orbital rim to camouflage the exposed orbital rim angle (B).

midface lift, the temples, forehead (including supraorbital and supratrochlear nerve blocks), zygoma and midface are infiltrated with the same solution.

\section{Transtemporal Subperiosteal Midface Lift}

The bilateral temporal incisions are placed $1 \mathrm{~cm}$ posterolateral to the temporal hairline and $1.5 \mathrm{~cm}$ inferior to the superior edge of the temporalis, extending $3 \mathrm{~cm}$ posteroinferiorly in length $[12,23]$. The medial incisions are placed $1 \mathrm{~cm}$ behind the frontal hairline aligned with the lateral limbus for use as endoscope entry sites and forehead periosteal fixation $[12,16]$. Through the temporal incision, blunt dissection is carried along the deep temporal fascia and medially across the temporal line. The arcus marginalis is released from its lateral end within $1 \mathrm{~cm}$ from the supraorbital neurovascular bundle $[12,16]$. When the plane of dissection from the superior and inferior pockets are connected over the deep temporalis fascia, several bridging veins are encountered before the sentinel vein is visualized at the junction of Pitanguy's line with the lateral orbital rim, which identifies the frontal branch of the facial nerve [23]. Using endoscopic guidance, the supratrochlear and supraorbital neurovascular bundles are directly visualized, and the bilateral corrugator supercilii muscles are resected along with the procerus $[12,16]$. Dissection is continued inferiorly along the deep layer of temporalis fascia deep to the intermediate fat pad to the superior aspect of the zygomatic arch, where the periosteum of the zygoma is entered on its superior edge anteriorly to avoid injury to the frontal branch of the facial nerve $[16,24]$.
The periosteum over the zygomatic arch is elevated, and subperiosteal dissection continues anteriorly to the orbital rim, maintaining a $1 \mathrm{~cm}$ cuff of attached periosteum around the lateral canthus to prevent eye distortion $[12,16,24]$. The tendinous attachments along the lateral maxilla are released, and the masseteric aponeurosis attachments to the inferior aspect of the zygomatic arch are severed [17,21,24]. The medial and lateral pockets are connected, completely releasing the midface and ensuring mobility of the malar fat pad and SOOF $[12,24]$.

While the midface lift is a fat-sparing procedure, in cases of severe pseudoherniation, a limited amount of orbital fat is removed through a transconjunctival approach without violation of the orbicularis muscle prior to midface suspension. Following midface suspension, the lower lid tension is such that exposure of the orbital fat becomes impossible. Resuspension of the midfacial tissues creates a sling that tightens the lower lid and the pseudoherniated fat pads, reducing the need for fat excision.

Five 0-0 vicryl sutures are used for the midface and temporal suspension. The first is passed through periosteum immediately lateral to zygomaticofacial foramen to the temporalis fascia, applying a superolateral lift vector on the midfacial tissues $[12,25]$. The second suture is placed superior to the frontal branch of the facial nerve and secured to the temporalis fascia $[12,25]$. The last 3 sutures are placed in the superficial temporal fascia of the anterior skin edge and secured to the deep temporalis fascia [12]. This suspension allows for the re-positioning of the SOOF and malar fat pads 

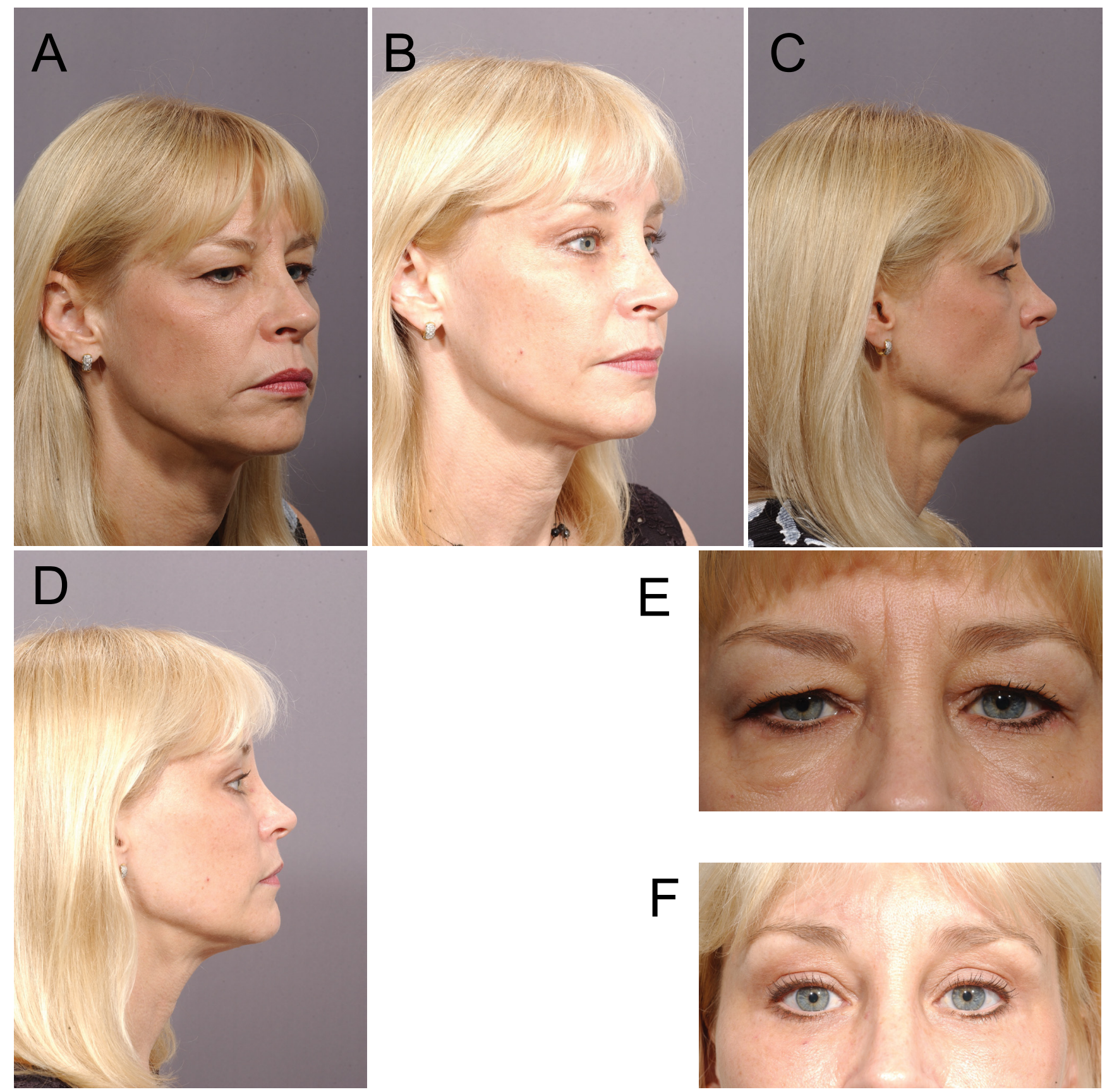

Figure 6: Grade III midfacial ptosis following a transtemporal subperiosteal midface lift with a transconjunctival lower lid blepharoplasty with skin pinch (and upper blepharoplasty).

A 51-year-old female underwent a midface lift for grade III midfacial ptosis. The orbital rim angle and the nasolabial folds are now effaced. The malar fat pads are in a more superior position, and the midface appear as a single convexity.

more superiorly, effacing the orbital rim and the nasolabial folds (Figure 6). Forehead fixation is performed with two $12 \mathrm{~mm}$ removable screws and a staple placed behind the screw to suspend the scalp superiorly [12]. The temporal incisions are then closed with 5-0 nylon using vertical mattresses. The elevation of the midface typically results in a bunching of excess skin at the lower eyelid, requiring a skin pinch excision to re-drape the skin [12]. The lower lid skin pinch involves only the superficial skin without violation of the orbicularis oculi, orbital septum or orbital fat [13].

\section{Lower Lid Blepharoplasty with Fat Transpo- sition}

The preference of the authors for the lower lid blepharoplasty with fat transposition is a subciliary incision immediately inferior to the lash margin although both transconjunctival and subciliary approaches have been described [26-28]. A skin-muscle flap is elevated in the submuscular plane to just beyond the inferior orbital rim [26]. At the orbital rim, the plane is elevated in the supraperiosteum and elevated bluntly. The orbital septum is preserved. 


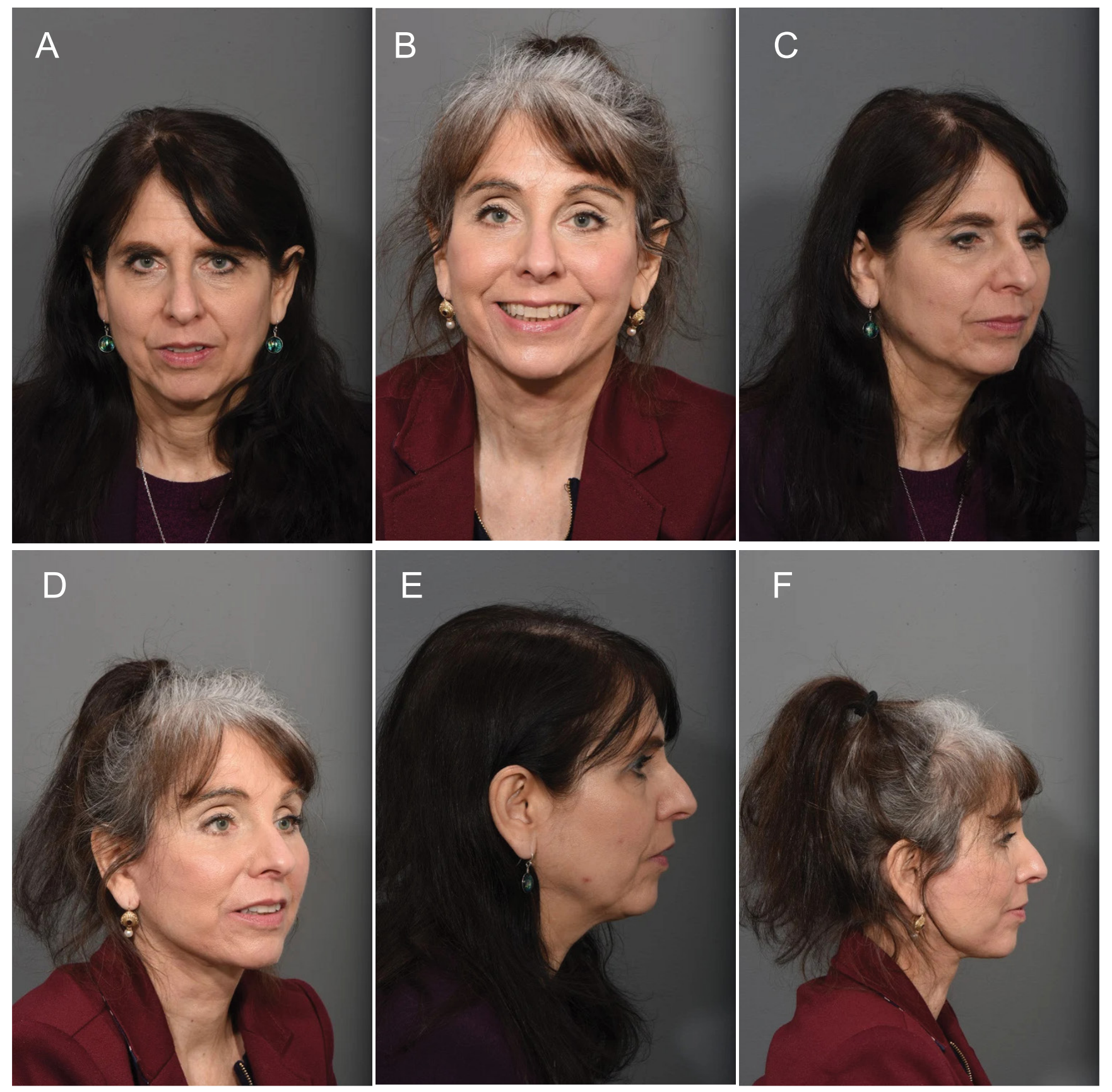

Figure 7: Grade II midfacial ptosis following a lower lid blepharoplasty with fat transposition (in addition to a deep plane rhytidectomy and endoscopic forehead lift with left orbicularis oculi myotomy).

A 61-year-old female with grade II midfacial ptosis underwent a lower lid blepharoplasty with fat transposition (and endoscopic brow lift with deep plane rhytidectomy). There is effacement of the orbital rim and a single convexity to the midface contour.

The medial, middle, and lateral fat pads are identified and meticulously released with blunt dissection. The fat pads are then repositioned along the length of the inferior orbital rim. Because of the deficiency of the SOOF medially, anchoring the orbital fat to the orbital rim (specifically to the periosteum) is not easy. Therefore, the medial fat pad and medial aspect of the middle fat pad are secured in position with 4-0 chromic sutures (Ethicon, Cincinnati, $\mathrm{OH}$ ) passed transcutaneously through the lower lid/cheek skin through the periosteum, securing the fat pad, and back out through the skin [13]. Each suture is secured to a cotton bolster on the skin surface.
The middle and lateral fat pads are fixed in position with 4-0 chromic sutures to the SOOF along the middle and lateral inferior orbital rim, respectively. The skin-muscle flap is redraped, and the excess skin is excised. The lateral aspect of the orbicularis oculi muscle along the deep surface of the skin-muscle flap is suspended to the lateral canthus with 6-0 nylon suture. This suspension suture helps prevent ectropion development and the need for a revision blepharoplasty with canthopexy (Figure 7). The skin is closed with 6-0 nylon and 7-0 silk (Ethicon) sutures. The bolster sutures are removed in 3 to 4 days at which point the fat pads have begun to scar 
in place over the inferior orbital rim [13]. In select patients without severe midfacial ptosis, a lower lid blepharoplasty with fat transposition serves as an acceptable alternative to efface an exposed orbital rim with an equal outcome of orbital rim angle improvement.

\section{Conclusion}

Midfacial aging encompasses ptosis of the malar fat pads, pseudohernation of orbital fat and exposure of the orbital rim. For patients with severe midfacial ptosis, the recommended optimal lifting technique per the authors is the transtemporal subperiosteal midface lift to efface the orbital rim angle, reposition the fat pads and rejuvenate the midface through the vertical shifting of midfacial soft tissue. However, in select patients with mild to moderate midfacial ptosis, a lower blepharoplasty with fat transposition serves as an acceptable alternative to address the double convexity contour of an exposed orbital rim. As described above, the two procedures have equally beneficial outcomes at improving the orbital rim angle and effacing the exposed orbital rim.

\section{References}

1. Wan D, Amirlak B, Rohrich R, et al. The clinical importance of the fat compartments in midfacial aging. Plast Reconstr Surg Glob Open 1: e92.

2. Wulc AE, Sharma P, Czyz CN (2012) The anatomic basis of midfacial aging. In: Hartstein ME, Wulc AE, Holck DEE, eds. Midfacial Rejuvenation : 15-28.

3. Furnas DW (1989) The retaining ligaments of the cheek. Plast Reconstr Surg 83: 11-16.

4. Stuzin JM, Baker TJ, Gordon HL (1992) The relationship of the superficial and deep facial fascias: Relevance to rhytidectomy and aging. Plast Reconstr Surg 89: 441-449.

5. Gosain AK, Amarante MT, Hyde JS, et al. (1996) A dynamic analysis of changes in the nasolabial fold using magnetic resonance imaging: implications for facial rejuvenation and facial animation surgery. Plast Reconstr Surg 98: 622-636.

6. Lambros $\vee$ (2007) Observations on periorbital and midface aging. Plast Reconstr Surg 120: 1367-1376.

7. Furnas D (1989) The Retaining Ligaments of the Cheek. Plast Reconstr Surg 83: 11-16.

8. Donofrio LM (2000) Fat distribution: A morphologic study of the aging face. Dermatol Surg 26: 1107-1112.

9. Rohrich RJ, Arbique GM, Wong C, et al. (2009) The anatomy of suborbicularis fat: Implications for periorbital rejuvenation. Plast Reconstr Surg 124: 946-951.

10. Mendelson B, Wong CH (2012) Changes in the facial skeleton with aging: Implications and clinical applications in facial rejuvenation. Aesthetic Plast Surg 36: 753-760.

11. Mendelson BC, Hartley W, Scott M, et al. (2007) Age-related changes of the orbit and midcheek and the implications for facial rejuvenation. Aesthetic Plast Surg 31: 419-423.

12. Shaw RB Jr, Katzel EB, Koltz PF, et al. (2011) Aging of the facial skeleton: Aesthetic implications and rejuvenation strategies. Plast Reconstr Surg 127: 374-383.

13. Quatela VC, Antunes MB (2015) Transtemporal midface lifting to blend the lower eyelid-cheek junction. Clin Plast Surg 42: 103114.

14. Weng C, Quatela V (2019) Achieving a Youthful Midface: Examination of Midface Anatomy Improvement Following Lower Blepharoplasty with Fat Transposition and Transtemporal Midface Lift With Lower Lid Skin Pinch. Aesthetic Surgery Journal 39: 416-428.

15. Hamra ST (1995) Arcus marginalis release and orbital fat preservation in midface rejuvenation. Plast Reconstr Surg 96: 354-362.

16. Hoenig JF, Knutti D, de la Fuente A (2011) Vertical subperiosteal mid-face-lift for treatment of malar festoons. Aesthetic Plast Surg 35: 522-529.

17. Graham HD, Quatela VC, Sabini P (2008) Chapter 20: Endoscopic approach to the brow and midface. In: Papel ID, ed. ( $3^{\text {rd }}$ edn), Facial Plastic and Reconstructive Surgery: 227-242.

18. Darcy SJ, Miller TA, Goldberg RA, et al. (2008) Magnetic resonance imaging characterization of orbital changes with age and associated contributions to lower eyelid prominence. Plast Reconstr Surg 122: 921-929.

19. Rohrich RJ, Pessa JE, Ristow B (2008) The youthful cheek and the deep medial fat compartment. Plast Reconstr Surg 121: 21072112.

20. Quatela VC, Ahmedli NN (2021) The Selection of Facelift Approach on the Basis of Midfacial Ptosis. Facial Plast Surg 37: 149-159.

21. Quatela V, Montague A, Manning JP, et al. (2020) Extended Superficial Musculoaponeurotic System Flap Rhytidectomy. Facial Plast Surg Clin North Am 28: 303-310.

22. Marotta JC, Quatela VC (2008) Lower eyelid aesthetics after endoscopic forehead midface-lift. Arch Facial Plast Surg 10: 267272.

23. Couch SM, Buchanan AG, Holds JB (2011) Orbicularis muscle position during lower blepharoplasty with fat repositioning. Arch Facial Plast Surg 13: 387-391.

24. Sabini P, Wayne I, Quatela VC (2003) Anatomical guides to precisely localize the frontal branch of the facial nerve. Arch Facial Plast Surg 5: 150-152.

25. Quatela VC, Jacono AA (2003) The extended centrolateral endoscopic midface lift. Facial Plast Surg 19: 199-208.

26. Quatela VC, Azzi JP, Antunes MB (2014) Endoscopic-assisted facelifting. Facial Plast Surg 30: 413-421.

27. Davison SP, lorio ML, Oh C (2015) Transconjunctival lower lid blepharoplasty with and without fat repositioning. Clin Plast Surg 42: 51-56.

28. Baker S, LaFerriere K, Larrabee WF Jr (2014) Lower lid blepharoplasty: Panel discussion, controversies, and techniques. Facial Plast Surg Clin North Am 22: 97-118.

29. Pepper JP, Baker SR (2015) Transcutaneous lower blepharoplasty with fat transposition. Clin Plast Surg 42: 57-62.

DOI: $10.36959 / 587 / 597$

Copyright: (C) 2021 Vito QC, et al. This is an open-access article distributed under the terms of the Creative Commons Attribution License, which permits unrestricted use, distribution, and reproduction in any medium, provided the original author and source are credited. 